\title{
Relationship between Olfactory Preferences and Olfactory Event-Related Potentials
}

\author{
Gil-Hyun Lee ${ }^{1, *}$, Hae-Gyung Yoon ${ }^{2, *}$, Young-Sam Kim ${ }^{3, *}$ and Kyung-Yae Hyun ${ }^{4, \dagger, *}$ \\ ${ }^{1}$ Department of Clinical Laboratory Science, Dong-Seo University, Busan 47011, Korea \\ ${ }^{2}$ Division of Basic Sciences, Dong-eui University, Busan 47340, Korea \\ ${ }^{3}$ Department of Art and Design, Dong-Eui University, Busan 47340, Korea \\ ${ }^{4}$ Department of Clinical Laboratory Science, Dong-Eui University, Busan 47340, Korea
}

\begin{abstract}
Quantitative evaluation of the sense of smell is done by the olfactory event-related potential (OERP) test. OERP consists of N1, P1, N2, P2, and P3, of which N1 and P1 latency are known to be affected by the concentration of odor stimuli associated with the pre-sensory phase and $\mathrm{P} 2$ and $\mathrm{P} 3$ are the stages at which odors are perceived and are known to change by subjective evaluation of the stimulus. The purpose of this study was to clarify the correlation between the expression of OERP and the subjective evaluation of the object on the fragrance stimulus using various fragrances. Therefore, the study examined the relative waveform power ratio, preference for each scent stimulus, and finally the amplitude and latency change of the components of OERP, N1 and P2. In contrast, it was found that the late $\mathrm{P} 2$ response waveform was an effective aroma stimulus recognition waveform in OERP compared to the initial response waveforms.
\end{abstract}

Key Words: OERP, EEG, BCI, ERP, N1, P2

\section{서 론}

후각 기관계(olfactory system)는 주 후각 기관과 부 후각 기관으로 구분된다. 이 중 부 후각 기관은 액체 입자의 자극에 반응하고, 주 후각 기관은 휘발성 기체 입자에 반 응한다고 알려져 있다(Dember et al., 1995). 인간은 주 후각 기관을 통하여 코를 통하여 흡입된 냄새물질에 반응하며, 흡입된 냄새물질은 후각 상피와 접촉하는데 후각 상피는 다수의 후각 감각 세포로 이루어져 있다. 냄새 자극을 받 은 후각 감각 세포는 사구체(glomerulus)를 통하여 승모 세포(mitral cell)에 신호를 전달하고, 이러한 전기적 자극 은 후각 신경섬유를 통하여 종뇌(telencephalon)의 다양한 부위에 전달된다(Firestein, 2001). 또한, 인간의 후각은 정
교한 감각 기관으로 수천 가지의 유기화합물을 구별할 수 있으며 후각은 감정과 밀접한 관련이 있다고 알려져 있다(Firestein, 2001). 다수의 연구자들이 후각 자극에 의한 감성과 감각의 변화를 객관화하고자 뇌파 검사 기법을 활용하고 있으며, 각 유도전극뇌전도(electroencephalography, $\mathrm{EEG}$ )의 fast fourier transform (FFT) 차이 분석과 각 $\mathrm{EEG}$ 파형에 대한 power spectrum의 변화 등이 연구에 활용되 었다(Kwon, 1994; Dember et al., 1995; Castle et al., 2000). 과 거 연구자들의 FFT와 power spectrum 비 분석은 냄새를 이용한 후각 유발 후 전반적인 뇌파의 변화 양상을 평가 하였다(Freeman and Viana Di Prisco 1986; Wu et al., 2012; Zhao et al., 2012).

사건유발전위(event-related potentials, ERP)는 어떠한 자 극에 대한 뇌 반응 결과로 나타나는 전위차를 말하여, 통

Received: November 19, 2019 / Revised: March 16, 2020 / Accepted: March 17, 2020

* Professor.

${ }^{\dagger}$ Corresponding author: Kyung-Yae Hyun. Department of Clinical Laboratory Science, Dong-Eui University, Busan 47340, Korea. Tel: +82-51-890-2683, Fax:+82-0505-182-6877, e-mail: kyhyun@deu.ac.kr

(C) The Korean Society for Biomedical Laboratory Sciences. All rights reserved.

(C) This is an Open Access article distributed under the terms of the Creative Commons Attribution Non-Commercial License (http://creativecommons.org/licenses/by-nc/3.0/) which permits unrestricted non-commercial use, distribution, and reproduction in any medium, provided the original work is properly cited. 
Table 1. Constituent of flavored aromatic oil

\begin{tabular}{ll}
\hline \hline \multicolumn{1}{c}{ Scientific name } & $\begin{array}{c}\text { General name } \\
\text { (percent concentration) }\end{array}$ \\
\hline Rosmarinus officinalis L. & Rosemary (10\%) \\
Pelargonium capitatum & Rose Geranium (3\%) \\
Lavandula officnalis & Lavender (4\%) \\
Cinnamomum cassia Blume & Cinnamon (5\%) \\
Mentha piperita & Peppermint (1\%) \\
Ponus sylvestris & Pine leaf $(2 \%)$ \\
\hline
\end{tabular}

상 $\mathrm{EEG}$ 를 사용하여 측정한다. 후각사건유발전위(Olfactory event-related potentials, OERP)의 경우 유발 자극이 후각이 되며 후각 자극의 종류는 메탄올, 부탄 등과 같은 유기용 매, 혐오 화학물질, 그리고 상용화된 향기 제품 등 다양하 다(Sato et al., 1996). 현재는 brain-computer interface (BCl) 기 술의 발전과 더불어 다양한 인간의 오감에 대한 연구에 비침습적 방법으로 $\mathrm{EEG}$ 가 활용되고 있으며, 최근 연구에 서 OERP를 활용하기 시작하였으며, 이와 더불어 magnetic resonance imaging와 같은 최신 영상 장비를 이용한 향기 에 대한 뇌 활성 분포에 대한 연구 또한 활발히 진행 중 이다(Gottfried et al., 2002; Ishimaru et al., 2002; Croy et al., 2014; Nejati et al., 2015).

OERP는 N1, P1, N2, P2 그리고 P3로 구성되어 있으며 이 중 N1과 P1 잠복기는 외인성 인자(exogenous components)로 냄새를 맡게 되는 감각 전 단계와 관련된 냄새 자 극의 농도에 영향을 받는다고 알려진 반면, $\mathrm{P} 2$ 와 $\mathrm{P} 3$ 는 냄 새를 인지하기 시작하는 단계로 자극의 주관적 평가에 의 하여 변한다고 알려져 있다(Pause et al., 1996). 일반적으로 자극 향기의 농도가 높을수록 파형의 진폭은 높아지고 잠복기는 짧아진다는 연구 결과도 보고되었다(Tateyama et al., 1998).그리고 OERP의 결과는 나이에 따라 그 결과의 유의한 차이가 있다는 Evans의 보고가 있으며 이는 나이 가 들어감에 따라 후각감각수용체의 기능에 변화가 있어 서라고 예상된다(Evans et al., 1995). 해외에서는 OERP에 대한 연구가 다양한 분야(의료, 향수 산업 등)에서 진행되 었지만, 국내에서는 후각유발전위검사 혹은 후각사건전위 검사에 대한 학술연구가 극히 소수만 진행되었으며 이에 대한 기초 의학 데이터는 전무한 상태이다(Kwon, 1994).

본 연구는 여러 가지 향기에 대한 반응시간 및 향기의 대한 선호도와 후각유발전위의 객관적인 데이터 간의 관 계를 규명함으로 향후 후각유발전위의 의학적 기초자료

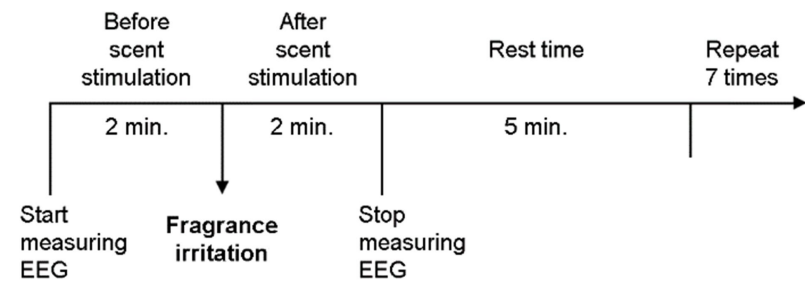

Fig. 1. Experiment Schedule. Aroma stimulation was given 2 minutes after EEG measurement. EEG was measured for 2 minutes and repeated 7 times. The number of odor stimuli per day was limited in consideration of olfactory fatigue.

의 토대를 쌓기 위하여 시행하였다.

\section{재료 및 방법}

\section{Participants}

20 대(23 \pm 1.3$)$ 남녀 30명을 대상으로 연구를 진행하였 다. 실험 전 설문을 통하여 흡연 경력, 감기, 비염, 알레르 기, 후각 통증이 있는 이들을 제외하였으며 실험 전 4시 간 동안 금식하였다(Table 1). 본 연구는 동의대학교 연구 윤리심의규정(DIRB-201911-HR-E-34)을 준수하여 시행하 였다.

\section{Experimental design}

$10 \mathrm{~m} \times 6 \mathrm{~m}$ 공간에서 실험 전 환기를 하고 실험을 시 작하였다. 향기 자극을 시행하기 앞서 뇌파 장비를 피험 자에게 장착하고 사용자 뇌파에 대한 calibration을 실시하 였다. 향기 자극 전 시간, 향기 자극 시간, 그리고 휴식 시간으로 구분하여 실험을 진행하였으며, 휴식 시간마다 실험 장소를 환기하였다. 피검자가 향기를 맡기 시작한 때 와 더 이상 향기를 맡지 못한 시기를 구분하기 위하여 향 기 인지 시작 시간과 향기 비인지 시작 시간에 검정 button을 누르게 하였다. 각 향기 자극 후 향기 자극에 대한 선호도(0 10점 척도, 0 점: 아주 싫음, 5 점: 보통, 10 점: 아주 좋음)를 설문 조사하였다(Table 2). Fig. 1에서 전체 실험 계 획에 대하여 도식화하여 설명하고 있다.

\section{Electroencephalography (EEG)}

뇌파는 국제 기준법인 10 20법 방법으로 부착하였다 (Homan et al., 1987). 뇌파 calibration을 실행하였으며 감도 는 $50 \mu \mathrm{V} / 5 \mathrm{~mm}$, 시정수는 0.3 초, 기록 속도는 $30 \mathrm{~mm} / \mathrm{sec}$, 그리고 고영역 차단 filter는 $100 \mathrm{~Hz}$ 로 설정하였다(Nuwer 
et al., 1998). 활성 전극은 F (Frontal)z, C (Central)z, $\mathrm{P}$ (Parietal)z, T3 (Temporal), T4을 사용하였으며, 뇌파 부착 후 각 전극에서의 임피던스(impedance)를 $5 \mathrm{~K} \Omega$ 이하로 조정 하였다. 자율 신경의 활성도 평가를 위하여 목 경동맥 부 위에 측정 센서를 부착하였다(Hammond et al., 1992). 뇌 파 부착 및 정보수집 장비는 Quick-20 (Pelican products Torrance CA, USA)을 사용하였다.

\section{Odor stimulation}

6가지의 천연물질을 사용한 천연 향료는 네츄럴 솔루 션에서 공급받았으며, 향기 보존과 휘발성 부여를 위하여 글리세린과 변성알코올을 첨가하였다(Chung et al., 1999). 모든 향기의 농도는 XP-329IIIR (COSMOS, Japan)로 측정 하였으며, 가장 작은 농도를 기준으로 동등한 농도로 다 른 물질을 희석하여 사용하였다. 실험에 사용한 천연물질 향료는 Table 1 와 같다. 사각형의 거즈 $\left(25 \mathrm{~cm}^{2}\right)$ 에 천연향기 시료를 충분히 적신 후 conical tube 담아 코 앞 $2 \mathrm{~cm}$ 위 치에서 피검자의 후각을 자극하였다. 후각 자극은 안정기 뇌파 측정(2분), 후각자극유발(2분), 그리고 휴식(5분) 순 으로 총 9 분 동안 측정하였으며 각 향기 당 8 번 반복 측 정하였다(Masago et al., 2001; Cook et al., 2018). 여러 향기를 체험하게 되는 피검자가 격을 수 있는 후각피로현상을 줄이기 위하여 첫날에 2 가지 향료에 대한 자극에 대하여 실험하였으며, 이 후 일주일마다 2가지 향료에 대한 연구 를 진행하였다. 정제수와 변성알코올로 구성된 후각 자극 을 음성대조군으로 활용하였다.

\section{EEG data extraction and analysis}

전체 뇌파 측정 구간 내에서 상대적 $\alpha$ 파와 $\beta$ 파의 power spectrum 비(relative power ratio of $\alpha$ wave and $\beta$ ) 분석을 2단 계(안정기 뇌파, 후각 자극 유발 구간)로 구분하여 실행하 였다. 상대 power spectrum 비 분석을 위하여 활성 전극 $\mathrm{Fz}, \mathrm{Cz}, \mathrm{Pz}, \mathrm{T} 3, \mathrm{~T} 4$ 의 데이터를 활용하였다(Zhao et al., 2012). OERP 측정을 위하여 향기 유발 직전 1 초에서 향기 감 지 시간 직후 3 초까지의 뇌파 epoch를 추출하였다(Invitto and Grasso, 2019). 수집한 epoch를 band-pass filter를 이용하 여 1 20 Hz로 제한하였으며, reference interval은 자극 전 0.5 0초로 eye blank와 같은 잡음을 제거하기 위하여 파 형의 진폭이 -100 100 $\mu \mathrm{V}$ 로 제한하였다(Han et al., 2017). 각각의 피검자에게서 수집된 모든 OERP epoch $(n=56)$ 를 이용하여 평준화 과정을 실행하였으며, 배경 및 인공 산 물 제거될 때까지 반복 실험을 진행하였다(Hawkes and
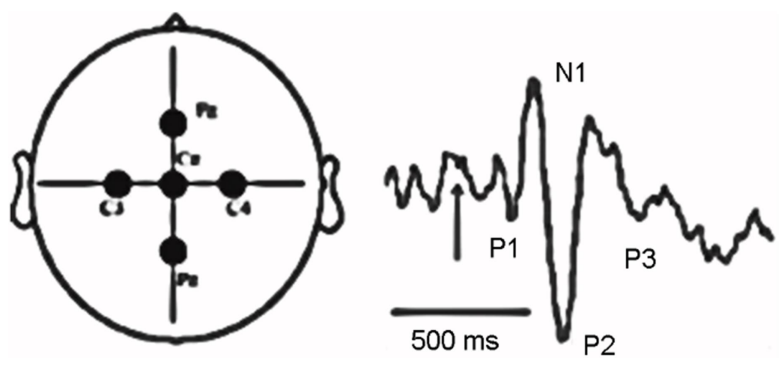

Fig. 2. ERP basic waveform.

Doty, 2009). 일반적으로 평준화된 OERP 파형에서 P2의 잠복기는 자극 유발 후 530 800 ms이며, $\mathrm{N} 1 \sim \mathrm{P} 2$ 파형의 진폭은 4 20 $\mu \mathrm{V}$ 라고 알려져 있으며(Caminiti et al., 2014), 이를 기준으로 epoch에서 각 잠복기를 구분하였다(Fig. 2). BrainMap-3D program (LAXTHA inc.USA)을 이용하여 OERP 파형의 추출 및 평준화를 실시하였다.

\section{Statistical processing}

모든 데이터는 평균(mean) \pm 표준편차(SD) 형태로 표현 하였다. 안정기 뇌파와 후각 자극 유발 후 상대적 power spectrum 비의 변화를 unpaired $t$-test로 평가하였다. 향기에 대한 선호도와 각 뇌파와의 상관성을 평가하기 위하여 Pearson correlation analysis을 실시하였으며 OERP의 상관성 분석은 파형 성분의 잠복기와 진폭을 성분으로 상관성을 조사하였다. 향기 자극 전후 차이 분석은 paired $t$-test로, 각 향기 간 뇌파 요소 사이의 차이는 ANOVA를 이용하 여 비교 분석하였으며, Turkey's method를 이용하여 각 군 을 사후 검정하였다. 모든 통계 분석은 SPSS 20.0 program 을 이용하여 실행하였다.

\section{결 과}

\section{Affinity for fragrance}

Table 2 의 결과에 따르면 향기에 대한 선호도는 성별의 차이가 없음을 알 수 있었다. 향기 선호도는 Cinnamon, Peppermint, pine leaf, Rose Geranium, Rose Geranium, Rosemary, Lavender 순서였다. Lavender 자극에서 가장 큰 호응도 $(8.9 \pm 1.8$ 점)를 보였으며, Cinnamon 자극에서 가장 낮은 호응도(1.2 \pm 0.6$)$ 가 나타남을 알 수 있었다.

\section{Relative power ratio}

상대적 $\alpha$ 파와 $\beta$ 파의 power spectrum 비는 모든 전극에 
Table 2. General characteristics of subject and preference score

\begin{tabular}{|c|c|c|c|c|c|}
\hline \multirow{2}{*}{ Subject factors } & \multicolumn{2}{|l|}{ Contents } & \multirow{2}{*}{$\begin{array}{l}\text { Flavored aromatic oils } \\
\text { (Abbreviation) }\end{array}$} & \multicolumn{2}{|c|}{ Preference score } \\
\hline & Gender & Total & & Gender & Total \\
\hline \multirow{2}{*}{ Sex (numbers) } & $12(46.6 \%)$ & \multirow{2}{*}{-} & \multirow{2}{*}{ Rosemary (ROE) } & Men $\quad 7.6 \pm 1.2$ & \multirow{2}{*}{$7.4 \pm 1.6$} \\
\hline & Women $18(53.4 \%)$ & & & Women $7.3 \pm 2.0$ & \\
\hline \multirow{2}{*}{ Age (numbers) } & $23.2 \pm 1.4$ & \multirow{2}{*}{$22.2 \pm 0.9$} & \multirow{2}{*}{ Rose Geranium (PGE) } & Men $\quad 6.4 \pm 2.4$ & \multirow{2}{*}{$6.7 \pm 2.0$} \\
\hline & Women $21.6 \pm 0.8$ & & & Women $6.9 \pm 1.6$ & \\
\hline \multirow{2}{*}{$\begin{array}{l}\text { Smoking or not } \\
\text { (numbers) }\end{array}$} & Men $\quad 0(0.0 \%)$ & \multirow{2}{*}{$36.6 \%$} & \multirow{2}{*}{ Lavender (LOE) } & Men $\quad 8.7 \pm 2.5$ & \multirow{2}{*}{$8.9 \pm 1.8$} \\
\hline & Women $0(0.0 \%)$ & & & Women $9.1 \pm 1.4$ & \\
\hline \multirow{2}{*}{ Drinking (numbers) } & Men $\quad 12(100.0 \%)$ & \multirow{2}{*}{$93.3 \%$} & \multirow{2}{*}{ Cinnamon (CVE) } & Men $\quad 1.5 \pm 0.4$ & \multirow{2}{*}{$1.2 \pm 0.6$} \\
\hline & Women $16(88.9 \%)$ & & & Women $1.0 \pm 0.7$ & \\
\hline \multirow{2}{*}{$\begin{array}{l}\text { Olfactory medical history } \\
\text { (numbers) }\end{array}$} & Men $\quad 2(16.7 \%)$ & \multirow{2}{*}{$26.7 \%$} & \multirow{2}{*}{ Peppermint (MPE) } & Men $\quad 3.3 \pm 1.0$ & \multirow{2}{*}{$3.5 \pm 0.8$} \\
\hline & Women $6(33.3 \%)$ & & & Women $3.7 \pm 0.7$ & \\
\hline \multirow{2}{*}{$\begin{array}{l}\text { Dizziness or not } \\
\text { (numbers) }\end{array}$} & Men $\quad 1(8.3 \%)$ & \multirow{2}{*}{$10.0 \%$} & \multirow{2}{*}{ Pine leaf(PSE) } & Men $\quad 5.8 \pm 0.9$ & \multirow{2}{*}{$5.4 \pm 1.3$} \\
\hline & Women $2(11.1 \%)$ & & & Women $5.2 \pm 1.6$ & \\
\hline \multirow{2}{*}{$\begin{array}{l}\text { Sinusitis or not } \\
\text { (numbers) }\end{array}$} & Men $\quad 0(0.0 \%)$ & \multirow{2}{*}{$0.0 \%$} & \multirow{2}{*}{$\begin{array}{l}\text { Negative control } \\
\text { (N.Control) }\end{array}$} & Men $\quad 4.5 \pm 1.3$ & \multirow{2}{*}{$4.6 \pm 1.2$} \\
\hline & Women $0(0.0 \%)$ & & & Women $4.7 \pm 1.2$ & \\
\hline
\end{tabular}

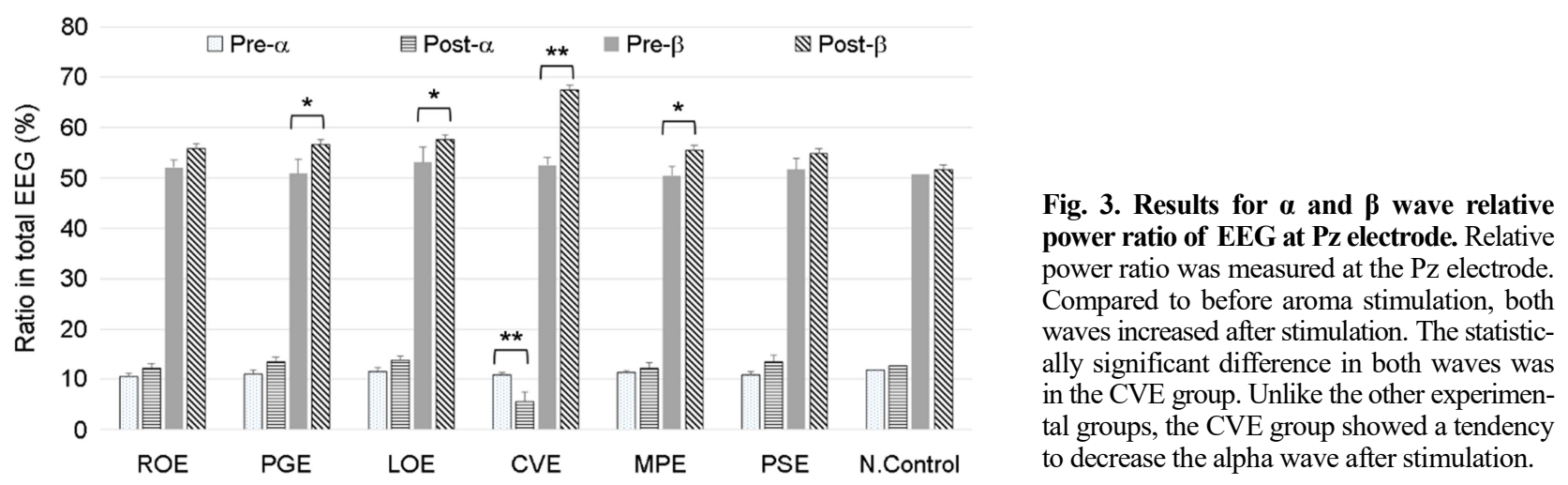

서 측정하였으며, 이 중 파형 결과가 가장 파형이 선명한 유도 전극인 Pz에서의 상대 power spectrum 비를 Fig. 3에 표시하였다. 분석 결과 $\mathrm{CVE}$ 군을 제외하고 모든 향기 자 극 군에서 향기 자극 후 3 분 동안 $\alpha$ 파의 power spectrum 비는 증가하였지만, $\beta$ 파 비는 감소하였다. 두 파형 모두 통계적으로 유의한 차이를 보인 군은 $\mathrm{CVE}$ 군 뿐이였다. $\mathrm{CVE}$ 군에서 상대적 $\alpha$ 파 비는 다른 군들과 다르게 향기 노 출 전(10.8 $\pm 1.5 \%)$ 에 비하여 향기 자극 후 $(5.6 \pm 1.8 \%)$ 줄어들었다 $(P<0.01)$. 분석 epoch의 시점을 향기 인지 시작 부터 향기를 인지하지 못하는 시점까지 제한하여 분석한 결과는 Fig. 3와 비교하여 다른 양상을 보임을 알 수 있 었다(Table 3). 후각 감수성이 존재하는 동안의 파형 비는
Fig. 3의 결과와 비교하여 상대적 $\alpha$ 파 비가 ROE군, PGE군, 그리고 $\mathrm{LOE}$ 군에서 증대하였음을 알 수 있었다 $(P<0.01)$.

\section{Mean amplitude and latency of olfactory event related potential (OERP)}

평준화된 OERP 파형에서 $\mathrm{N} 1, \mathrm{P} 1, \mathrm{~N} 2$, 그리고 $\mathrm{P} 2$ 중 내 인성 인자인 $\mathrm{N} 1$ 과 외인성 인자인 $\mathrm{P} 2$ 의 잠복기와 진폭을 분석하였다. Table 3 에서는 $\mathrm{Fz}, \mathrm{Cz}, \mathrm{Pz}, \mathrm{T} 3$, 그리고 $\mathrm{T} 4$ 의 추 출한 모든 epoch에서 평준화 과정을 거친 후 명료한 결 과를 보인 $\mathrm{Cz}$ 의 분석 결과를 보여준다.

$\mathrm{CVE}$ 군을 제외한 모든 실험 군 사이의 잠복기는 통계 적으로 유의한 차이가 없었으며, 별다른 경향성도 보이지 
Table 3. Relative $\alpha$ and $\beta$ wave spectral ratio at Pz electrode within limited range

\begin{tabular}{lcccl}
\hline \hline Groups & $\begin{array}{c}\text { Pre- } \alpha \text { wave ratio } \\
(\text { Recognition time }(\mathrm{sec}))\end{array}$ & $\begin{array}{c}\text { Post- } \alpha \text { wave ratio } \\
\text { (Recognition time }(\mathrm{sec}))\end{array}$ & $\begin{array}{c}\text { Pre- } \beta \text { wave ratio } \\
(\text { Recognition time }(\mathrm{sec}))\end{array}$ & $\begin{array}{c}\text { Post } \beta \text { wave ratio } \\
(\text { Recognition time }(\mathrm{sec}))\end{array}$ \\
\hline ROE & $10.6 \pm 1.6(120)$ & $18.0 \pm 4.2^{* *}(35.5 \pm 5.4)$ & $52.1 \pm 2.5(120)$ & $54.0 \pm 8.1(35.5 \pm 5.4)$ \\
PGE & $11.1 \pm 1.7(120)$ & $17.6 \pm 5.0^{* *}(21.5 \pm 7.9)$ & $50.9 \pm 3.8(120)$ & $55.6 \pm 7.0^{*}(21.5 \pm 7.9)$ \\
LOE & $11.5 \pm 2.8(120)$ & $19.6 \pm 7.7^{* *}(42.1 \pm 10.1)$ & $53.1 \pm 4.1(120)$ & $58.2 \pm 9.1^{*}(42.1 \pm 10.1)$ \\
CVE & $10.8 \pm 1.5(120)$ & $4.2 \pm 3.8^{* *}(55.5 \pm 12.6)$ & $52.6 \pm 2.5(120)$ & $68.2 \pm 15.7^{* *}(55.5 \pm 12.6)$ \\
MPE & $11.3 \pm 1.4(120)$ & $14.1 \pm 4.8(40.0 \pm 6.7)$ & $50.5 \pm 2.8(120)$ & $52.9 \pm 10.0(40.0 \pm 6.7)$ \\
PSE & $10.9 \pm 2.2(120)$ & $13.8 \pm 6.5(28.6 \pm 7.3)$ & $51.7 \pm 3.2(120)$ & $48.9 \pm 12.7(28.6 \pm 7.3)$ \\
N.Control & $11.7 \pm 2.0(120)$ & $12.5 \pm 5.8(31.5 \pm 4.0)$ & $50.8 \pm 2.8(120)$ & $55.4 \pm 8.4(31.5 \pm 4.0)$ \\
\hline
\end{tabular}

Before and after comparison of alpha and beta waves in Pz was performed by paired $t$-test, * means $P<0.05$, ** means $P<0.01$

Table 4. Mean amplitude and latency of OERNs in Cz electrode

\begin{tabular}{lcccc}
\hline \hline Groups & $\begin{array}{c}\text { Pre-N1 amplitude } \\
\text { (latency }(\mathrm{msec}))\end{array}$ & $\begin{array}{c}\text { Post-N1 amplitude } \\
(\text { latency }(\mathrm{msec}))\end{array}$ & $\begin{array}{c}\text { Pre-P2 amplitude } \\
\text { (latency }(\mathrm{msec}))\end{array}$ & $\begin{array}{c}\text { Post-P2 amplitude } \\
(\text { latency }(\mathrm{msec}))\end{array}$ \\
\hline ROE & $4.6 \pm 1.9^{\mathrm{a}}$ & $8.6 \pm 2.0^{* * \mathrm{a}, \mathrm{b}}$ & $5.8 \pm 0.9^{\mathrm{a}}$ & $12.0 \pm 3.0^{* * \mathrm{~b}}$ \\
& $(342.5 \pm 21.0)^{\mathrm{a}, \mathrm{b}}$ & $(346.0 \pm 16.9)^{\mathrm{c}}$ & $(697.0 \pm 16.4)$ & $(703.1 \pm 12.5)^{\mathrm{c}, \mathrm{d}}$ \\
PGE & $4.8 \pm 0.8^{\mathrm{a}, \mathrm{b}}$ & $9.0 \pm 1.2^{* * \mathrm{~b}, \mathrm{c}}$ & $5.7 \pm 1.4^{\mathrm{a}}$ & $13.6 \pm 3.0^{* * \mathrm{~b}}$ \\
& $(335.5 \pm 15.9)^{\mathrm{a}}$ & $(337.0 \pm 12.4)^{\mathrm{b}}$ & $(705.5 \pm 16.2)$ & $(701.0 \pm 10.9)^{\mathrm{c}}$ \\
LOE & $4.7 \pm 1.1^{\mathrm{a}}$ & $10.4 \pm 1.7^{* * \mathrm{~b}, \mathrm{c}}$ & $5.4 \pm 0.9^{\mathrm{a}}$ & $13.2 \pm 4.1^{* * \mathrm{~b}}$ \\
& $(340.9 \pm 10.8)^{\mathrm{a}, \mathrm{b}}$ & $(342.1 \pm 9.7)^{\mathrm{b}, \mathrm{c}}$ & $(708.1 \pm 13.5)$ & $(711.2 \pm 8.8)^{\mathrm{d}}$ \\
CVE & $4.8 \pm 0.8^{\mathrm{a}, \mathrm{b}}$ & $16.6 \pm 2.3^{* * \mathrm{~d}}$ & $5.8 \pm 1.0^{\mathrm{a}}$ & $26.2 \pm 2.7^{* * \mathrm{~d}}$ \\
& $(339.5 \pm 7.4)^{\mathrm{a}}$ & $(305.6 \pm 14.9)^{* * \mathrm{a}}$ & $(699.3 \pm 9.0)$ & $(642.0 \pm 9.4)^{* * \mathrm{a}}$ \\
MPE & $5.0 \pm 1.0^{\mathrm{b}}$ & $10.3 \pm 1.6^{* * \mathrm{~b}, \mathrm{c}}$ & $5.6 \pm 1.3^{\mathrm{a}}$ & $16.5 \pm 4.8^{* * \mathrm{c}}$ \\
& $(343.2 \pm 9.2)^{\mathrm{a}, \mathrm{b}}$ & $(340.6 \pm 11.0)^{\mathrm{b}, \mathrm{c}}$ & $(703.7 \pm 11.6)$ & $(681.9 \pm 16.7)^{* \mathrm{~b}, \mathrm{c}}$ \\
PSE & $4.7 \pm 0.6^{\mathrm{a}}$ & $11.2 \pm 0.9^{* * \mathrm{a}, \mathrm{b}}$ & $5.7 \pm 0.6^{\mathrm{a}}$ & $15.9 \pm 3.3^{* * \mathrm{~b}, \mathrm{c}}$ \\
& $(346.9 \pm 12.2)^{\mathrm{b}}$ & $(348.6 \pm 13.3)^{\mathrm{c}}$ & $(706.0 \pm 13.1)$ & $(677.0 \pm 11.1)^{* \mathrm{~b}}$ \\
N.Control & $4.9 \pm 0.8^{\mathrm{b}}$ & $6.5 \pm 1.58^{\mathrm{a}}$ & $5.9 \pm 1.3^{\mathrm{a}, \mathrm{b}}$ & $8.4 \pm 2.9^{\mathrm{a}}$ \\
& $(337.9 \pm 13.3)^{\mathrm{a}}$ & $(329.5 \pm 16.8)^{\mathrm{b}}$ & $(700.0 \pm 10.2)$ & $(689.1 \pm 13.8)^{\mathrm{b}}$ \\
\hline
\end{tabular}

Before and after comparison of latency and amplitude was performed by paired $t$-test, * means $P<0.05$, ** means $P<0.01$

The comparison between the groups was analyzed using ANOVA, and the results of the post-test showed that the groups sharing the same alphabet had no difference in means $(P>0.05)$. latency and amplitude

Table 5. Correlations among variables

\begin{tabular}{lcr}
\hline \hline \multicolumn{1}{c}{ Variables } & Coefficient of correlation & $P$ \\
\hline Olfactory Preferences $\leftrightarrow$ OERP N1 (pre - post) latency difference & 0.53 & 0.12 \\
Olfactory Preferences $\leftrightarrow$ OERP P2 (pre - post) latency difference & 0.62 & $<0.01$ \\
Olfactory Preferences $\leftrightarrow$ OERP N1 (pre - post) amplitude difference & 0.37 & 0.21 \\
Olfactory Preferences $\leftrightarrow$ OERP P2 (pre - post) amplitude difference & -0.76 & $<0.01$ \\
\hline
\end{tabular}

않았다. 진폭의 경우 음성대조군을 제외한 모든 군에서 유 의한 차이를 보였으며, 안정 구간보다 향기 자극 후 구간 에서 $\mathrm{N} 1$ 과 $\mathrm{P} 2$ 의 진폭이 증가함을 알 수 있었다 $(P<0.05)$. $\mathrm{N} 1$ 의 평균 잠복기는 약 $340 \mathrm{~ms}$ 구간에서 $\mathrm{P} 2$ 의 잠복기는 약 $710 \mathrm{~ms}$ 구간에서 형성되었다.

\section{Relationship between Olfactory Preferences and OERP}

선호도 점수(0 10점 척도)와 Table 3와 4의 변수들 간의 관계를 pearson의 상관 분석을 이용하여 분석하였다. Table 
5 에 의하면 선호도 점수는 진폭의 차와 잠복기(자극 전과 자극 후 차이) 사이에 강한 상관관계 $\left[r_{\text {진폭 }}\right.$ 상관계수 $)=$ $\left.0.76, P<0.01, r_{\text {잠복기 }}=0.62, P<0.01\right]$ 이 있음을 알 수 있었 다. 그러나, $\mathrm{OERP}$ 와 상대적 $\alpha$ 와 $\beta$ 파 변화 량 사이의 상관 관계를 고려하여 편상관분석을 실시한 결과 편상관계는

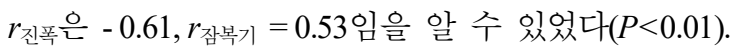

\section{고 찰}

후각 기능을 평가하는 기능 검사들은 청각 검사 등과 같은 다른 감각 기관 검사와 다르게 표준화되어 있지 않 은 실정이다. Sniffin' Sticks, Pennsylvania Smell Identification Test (UPSIT) 등과 같이 각 나라마다 다양한 방식들이 사 용되고 있지만 이러한 검사들은 순음 청력 검사와 같은 주관적인 검사들로 객관성이 떨어진다(Doty et al., 1984; Hummel et al., 1997). 1940년경 후각 자극이 다양한 전기 신호를 발생한다고 알려진 이 후 후각 기능을 평가하기 위한 뇌파를 이용한 다양한 연구가 시도되었으며(Allison and Goff, 1967), 연구자들은 후각 기능을 평가하기 위한 객관적인 지표를 마련하기 위하여 후각 유발 전위(olfactory evoked potential)를 후각 기능의 정량 검사 방법으로 이용하기 시작하였다(Tonoike et al., 1996).

강한 향기 자극은 농도에 따라 후각 신경과 함께 삼차 신경까지 흥분하게 할 수 있는 여지가 있다(Yang et al., 2001). 따라서, 본 연구에서 사용된 향기 자극들은 전 실 험을 통하여 삼차 신경을 흥분하질 않을 적절 농도를 안 면 신경전도 검사를 통하여 확인하였다. 향기 유입 방식 이 동일하다면 향기 자극은 공기 중 농도와 비례하므로 (Invitto and Grasso, 2019), 향기 자극 방법을 동일하게 적용 하고 $\mathrm{ppm}$ 을 측정하여 농도를 조절하였다. 연구에서 사 용된 향기의 자극 지속 시간은 향기 자극 종류에 따라 다양하였으며, 피검자의 후각예민도에 의해 결정되었다고 예상된다. 향기 자극 후 피검자의 만족도 평가를 보면, Lavender (LOE)에 대한 평가가 가장 높고 Cinnamon (CVE) 의 평가가 가장 낮음을 알 수 있었다. 향기 자극이 심리적 안정을 주는 경우 $\alpha$ 파의 발생이 증대한다는 전 연구들이 있으며(Manley, 1993; Brauchli et al., 1995), 본 연구에서도 향기 자극 후 2 분 동안 $\alpha$ 파가 증가하는 경향이 있음을 알 수 있었다 $(P>0.05)$ (Fig. 3). $\beta$ 파의 경우 향기 자극이 인 지적 영역에 미치는 영향과 관련이 있다고 알려져 있다 (Vanderwolf and Zibrowski, 2001). 후각 자극에 강도 및 기 억과 관련된 $\beta$ 파 발현은 본 연구에서는 선호도가 높은
혹은 낮은 실험군에서 통계적으로 유의한 차이를 보이며 상승함을 알 수 있었다.

소위 좋지 않은 향기, 냄새, 악취라고 명칭되는 향기는 P300 (P1)과 N400 (N1)를 이용한 다수의 연구가 과거부터 실행되었지만 다른 향기 종류와 별다른 차이가 없다고 알 려져 있었다(Yang et al., 2001; Invitto and Grasso, 2019). 천 연물 색소 향료를 이용한 P300 연구에 다소 차이가 발생 한다는 발표(Sano et al., 2002)가 있었지만 P2 (500 800 ms) 에 대한 활용도가 피검자의 향기를 인지하는 감정과 관 련된 주관적인 평가가 가미된다고 알려져 있어 임상 후 각 평가에서는 사용이 되어 왔다. 본 연구에서 이러한 향 기에 대한 피검자의 태도가 영향을 미치는 P2 성향을 선 호도와 상관성이 있을 것이라는 가설 아래 실행되었으며 그 결과는 Table 4와 같다. 음성대조군을 제외한 모든 군 에서 N1 진폭의 변화는 향기 자극 후 유의한 차이가 발 생함을 알 수 있었다. 통상 향기 자극을 느끼기 전인 전 감각 단계와 관련된 외인성 인자 성분인 $\mathrm{N} 1$ 성분 변화 정도는 본 연구에서 $\mathrm{CVE}$ 향기 자극을 제외하고 사용된 물질의 종류와는 관계가 없이 일정함을 알 수 있었다. 역 시 $\mathrm{CVE}$ 향기 자극을 제외하고 나머지 향기 자극들은 N1 과 P3 성분의 잠복기 역시 자극 전·후 사이의 차이가 없 음을 알 수 있었으며, 이는 좋지 않는 향기에 의한 후각 자극의 촉발 시간이 그렇지 않는 향기(좋은 향기, 보통 향기)에 비하여 촉발 시간이 빠르다고 사료될 수 있는 결 과이다. 본 연구에서 특이한 사항은 낮은 선호도를 점수 를 획득한 $\mathrm{CVE}$ 의 $\mathrm{P} 2$ 진폭 변화 결과이다. 선호도가 높은 $\mathrm{PGE}$ 와 LOE와 다르게 P3 변화폭이 상대적으로 매우 크 다는 것을 알 수 있었다. 과거의 다른 연구들 중 좋은 향 기와 좋지 않는 향기를 이용한 OERP의 결과는 연구의 목 적, 유발 상황, 분석 방법의 차이에 다르기 때문에 다소 애모모호면이 있다. 하지만, 대부분 연구들 중 공통되는 결과는 좋지 않은 향기가 다른 향기에 비하여 뇌파 전도 속도가 빠르다는 점과 좋지 않은 향기는 얼굴에 감정 표 현을 유발하므로 후기 유발 파의 진폭이 크다는 점에서 공통점이 있었다(Bensafi et al., 2002; Cook et al., 2017). 본 연 구 결과 역시 이러한 관점에서 보면 선호도가 낮은 $\mathrm{CVE}$ 가 잠복기와 진폭이 다른 점은 경향이 유사하지만, 진폭 의 차이가 다른 연구들과 비교하여 크다는 사실은 의아 한 결과이다. 다른 연구에서 사용된 화학적 악취물질에 비하여 그 악취도 낮은 $\mathrm{CVE}$ 향기 자극이 진폭 차이가 크 다는 것은 현재 일원화된 좋지 않는 향기가 작용하는 감 각 전달체계와는 다른 방식의 생리적 기전이 존재할 수 
도 있다고 의심하는 바이며 이는 향후 연구과제이다.

마지막으로 향기 자극과 선호도와의 상관성에 대한 결 과를 살펴보면, pearson 상관분석 결과 OERP의 진폭은 음 의 상관관계, 잠복기는 양의 상관관계가 있음을 알 수 있 었다. 타 연구에서 고려하는 호흡이나 얼굴 움직임에 의 한 인공 산물에 대한 고려는 low-high filter 조절을 통하여 제거한 후 분석을 실시하였다(Covington et al., 1999). 아쉬 운 점은 다양한 향기를 활용하였기 때문에 향기에 대한 기준(좋음: 0 , 나쁨: 1 )이 개개인 별로 차이가 있어 ROC curve 결과(평균 AUC: $0.41, P=0.08$, all data not shown)가 통계적으로 유의하지 못한 점이다.

본 연구는 다양한 향기를 사용하여 향기 자극에 대한 객체의 주관적인 평가에 대한 OERP의 발현과의 상관성 을 밝히고자 실행하였으며, 그 결과 선호도가 낮은 향기 자극에 대한 반응이 타 향기 종류와 다르다는 것을 알 수 있었으며, 초기 반응 파형들에 비하여 후기 P2 반응 파형 이 OERP에서 효과적인 향기 자극 인지 파형이다는 사실 을 알 수 있었다.

\section{ACKNOWLEDGEMENT}

None.

\section{CONFLICT OF INTEREST}

No potential conflict of interest relevant to this article was reported.

\section{REFERENCES}

Allison T, Goff W. Human cerebral evoked responses to odorous stimuli. Electroencephalography and Clinical Neurophysiology. 1967. 23: 558-560.

Bensafi M, Pierson A, Rouby C, Farget V, Bertrand B, Vigouroux M, Jouvent R, Holley A. Modulation of visual event-related potentials by emotional olfactory stimuli. Neurophysiologie Clinique/Clinical Neurophysiology. 2002. 32: 335-342.

Brauchli P., Rüegg PB, Etzweiler F, Zeier H. Electrocortical and autonomic alteration by administration of a pleasant and an unpleasant odor. Chemical Senses. 1995. 20: 505-515.

Caminiti F, De Salvo S, De Cola MC, Russo M, Bramanti P, Marino $\mathrm{S}$, Ciurleo R. Detection of olfactory dysfunction using olfactory event related potentials in young patients with multiple sclerosis. PLoS One. 2014. 9: e103151.

Castle P, Van Toller S, Milligan G. The effect of odour priming on cortical EEG and visual ERP responses. International Journal of Psychophysiology. 2000. 36: 123-131.

Chung HR, Lee JY, Kim DC, Hwang WI. Synergistic effect of Panax ginseng and Cinnamoum Blume mixture on the inhibition of cancer cell growth in vitro. Journal of Ginseng Research. 1999. 23: 99-104.

Cook S, Kokmotou K, Soto V, Fallon N, Tyson-Carr J, Thomas A, Giesbrecht T, Field M, Stancak A. Pleasant and unpleasant odour-face combinations influence face and odour perception: an event-related potential study. Behavioural Brain Research. 2017. 333: 304-313.

Cook S, Kokmotou K, Soto V, Wright H, Fallon N, Thomas A, Giesbrecht T, Field M, Stancak A. Simultaneous odour-face presentation strengthens hedonic evaluations and event-related potential responses influenced by unpleasant odour. Neuroscience Letters. 2018. 672: 22-27.

Covington JW, Geisler MW, Polich J, Murphy C. Normal aging and odor intensity effects on the olfactory event-related potential. International Journal of Psychophysiology. 1999. 32: 205 -214 .

Croy I, Schulz M, Blumrich A, Hummel C, Gerber J, Hummel T. Human olfactory lateralization requires trigeminal activation. Neuroimage. 2014. 98: 289-295.

Dember WN, Warm JS, Parasuraman R. Olfactory stimulation and sustained attention. Compendium of Olfactory Research. 1995. IA: 39-46.

Doty RL, Shaman P, Kimmelman CP, Dann MS. University of Pennsylvania Smell Identification Test: a rapid quantitative olfactory function test for the clinic. The Laryngoscope. 1984. 94: 176-178.

Evans WJ, Cui L, Starr A. Olfactory event-related potentials in normal human subjects: effects of age and gender. Electroencephalography and Clinical Neurophysiology. 1995. 95: 293 -301 .

Firestein S. How the olfactory system makes sense of scents. Nature 2001. 413: 211.

Freeman WJ, Viana Di Prisco G. Relation of olfactory EEG to behavior: time series analysis. Behavioral Neuroscience. 1986. 100: 753 .

Gottfried JA, O'Doherty J, Dolan RJ. Appetitive and Aversive Olfactory Learning in Humans Studied Using Event-Related Functional Magnetic Resonance Imaging. The Journal of Neuroscience. 2002. 22: 10829-10837.

Hammond EJ, Uthman BM, Reid SA, Wilder B. Electrophysiological studies of cervical vagus nerve stimulation in humans: 
I. EEG effects. Epilepsia. 1992. 33: 1013-1020.

Han P, Schriever VA, Peters P, Olze H, Uecker FC, Hummel T. Influence of airflow rate and stimulus concentration on olfactory event-related potentials (OERP) in humans. Chemical Senses. 2017. 43: 89-96.

Hawkes CH, Doty RL. The neurology of olfaction, Cambridge University Press. 2009.

Homan RW, Herman J, Purdy P. Cerebral location of international 10 20 system electrode placement. Electroencephalography and Clinical Neurophysiology.1987. 66: 376-382.

Hummel T, Sekinger B, Wolf SR, Pauli E, Kobal G. 'Sniffin'sticks': olfactory performance assessed by the combined testing of odor identification, odor discrimination and olfactory threshold. Chemical Senses. 1997. 22: 39-52.

Invitto S, Grasso A. Chemosensory Perception: A Review on Electrophysiological Methods in "Cognitive Neuro-Olfactometry". Chemosensors. 2019. 7: 45.

Ishimaru T, Miwa T, Shimada T, Furukawa M. Electrically stimulated olfactory evoked potential in olfactory disturbance. Annals of Otology, Rhinology \& Laryngology. 2002. 111: 518-522.

Kwon JS. Clinical Applications of Event-related Potentials. Sleep Medicine and Psychophysiology. 1994. 1: 36-46.

Manley CH. Psychophysiological effect of odor. Critical Reviews in Food Science and Nutrition. 1993. 33: 57-62.

Masago R, Shimomura Y, Iwanaga K, Katsuura T. The Effects of Hedonic Properties of Odors and Attentional Modulation on the Olfactory Event-Related Potentials. Journal of Physiological Anthropology and Applied Human Science. 2001. 20: 7-13.

Nejati H, Tsourides K, Pomponiu V, Ehrenberg EC, Cheung NM, Sinha P. Towards perception awareness: Perceptual event detection for brain computer interfaces. 2015 37th Annual International Conference of the IEEE Engineering in Medicine and Biology Society (EMBC), IEEE. 2015.

Nuwer MR, Comi G, Emerson R, Fuglsang-Frederiksen A, Guérit JM, Hinrichs H, Ikeda A, Luccas FJC, Rappelsburger P. IFCN standards for digital recording of clinical EEG. Electroencephalography and Clinical Neurophysiology. 1998. 106: 259 -261 .
Pause BM, Sojka B, Krauel K, Ferstl R. The nature of the late positive complex within the olfactory event-related potential (OERP). Psychophysiology. 1996. 33: 376-384.

Sano K, Tsuda Y, Sugano H, Aou S, Hatanaka A. Concentration effects of green odor on event-related potential (P300) and pleasantness. Chemical Senses. 2002. 27: 225-230.

Sato M, Kodama N, Sasaki T, Ohta M. Olfactory evoked potentials: experimental and clinical studies. Journal of Neurosurgery. 1996. 85: 1122-1126.

Tateyama T, Hummel T, Roscher S, Post H, Kobal G. Relation of olfactory event-related potentials to changes in stimulus concentration. Electroencephalography and Clinical Neurophysiology/Evoked Potentials Section. 1998. 108: 449-455.

Tonoike M, Maeda A, Kawai H, Kaetsu I. Measurement of olfactory event-related magnetic fields evoked by odorant pulses synchronized with respiration. Electroencephalography and Clinical Neurophysiology. Supplement. 1996. 47: 143.

Vanderwolf $\mathrm{C}$, Zibrowski EM. Pyriform cortex $\beta$-waves: odorspecific sensitization following repeated olfactory stimulation. Brain Research. 2001. 892: 301-308.

Wu CH, Lee PL, Shu CH, Yang CY, Lo MT, Chang CY, Hsieh JC. Empirical mode decomposition-based approach for intertrial analysis of olfactory event-related potential features. Chemosensory Perception. 2012. 5: 280-291.

Yang KH, Lee JS, Huh NH, Choi SH, Park YM. Odorant Confusion Matrix Odor Identification Test Using Synthetic Odorants. Korean Journal of Otorhinolaryngology-Head and Neck Surgery. 2001. 44: 278-282.

Zhao C, Zhao M, Liu J, Zheng C. Electroencephalogram and electrocardiograph assessment of mental fatigue in a driving simulator. Accident Analysis \& Prevention. 2012. 45: 83-90.

https://oi.org/10.15616/BSL.2020.26.1.14

Cite this article as: Lee GH, Yoon HG, Kim YS, Hyun KY. Relationship between Olfactory Preferences and Olfactory Event-Related Potentials. Biomedical Science Letters. 2020. 26: 14-21. 